\title{
Trochlear Nerve Schwannoma Treated with Gamma Knife after Excision: A Case Report and Review of the Literature
}

\author{
Takuro Inoue ${ }^{1}$ Ayako Shima ${ }^{1}$ Hisao Hirai ${ }^{1}$ Fumio Suzuki ${ }^{1}$ Masayuki Matsuda ${ }^{1}$ \\ ${ }^{1}$ Department of Neurosurgery, Subarukai Kotoh Kinen Hospital, \\ Higashiohmi, Shiga, Japan \\ Address for correspondence Takuro Inoue, MD, PhD, 2-1 Hiramatsu- \\ cho, Higashiohmi-shi, Shiga 527-0134, Japan \\ J Neurol Surg Rep 2015;76:e248-e252. \\ (e-mail: takuro39@gmail.com).
}

\begin{abstract}
Trochlear nerve schwannomas are extremely rare. We present a surgically excised case of trochlear nerve schwannoma followed by Gamma Knife (ELEKTA, Stockholm, Sweden) after histologic confirmation. A 52-year-old man presented with diplopia, gait disturbance, and sensory disturbance. Magnetic resonance imaging demonstrated a large cystic mass at ambient cistern on the right side. Subtotal excision followed by

Keywords

- trochlear nerve

- schwannoma

- Gamma Knife

- radiosurgery Gamma Knife surgery was undertaken. His neurologic symptoms disappeared with radiologic reduction in size at 15 -month follow-up. Because Gamma Knife can manage trochlear nerve schwannomas well, surgical excision should be reserved for large ones and limited to subcapsular or subtotal removal with the expectation of possible recovery of neurologic dysfunction.
\end{abstract}

\section{Introduction}

Intracranial schwannomas arise mostly from the vestibular nerve. Nonvestibular schwannomas are rare, and trochlear schwannomas are extremely rare. Only 32 surgically resected cases are reported in the literature., ${ }^{1,2}$ Another 11 cases treated with Gamma Knife were found in our search, none of them are histologically confirmed. ${ }^{3-8}$ We present a case of histologically confirmed trochlear schwannoma followed by Gamma Knife surgery.

\section{Case Report}

A 52-year-old man without a remarkable medical history or neurofibromatosis had diplopia for 2 years. One month prior to his visit to our hospital, he experienced gait disturbance and sensory disturbance on the left side. Neurologic examinations revealed moderate right trochlear nerve palsy, slight left hemiparesis, a sensory disturbance on the left side of the body, left cerebellar ataxia, and truncal ataxia. Magnetic resonance imaging (MRI) disclosed a cystic tumor locating at the right ambient and prepontine cisterns, compressing

received

March 27, 2015

accepted after revision

July 17, 2015

published online

September 9, 2015
DOI http://dx.doi.org/ 10.1055/s-0035-1564059. ISSN 2193-6358. the cerebral peduncle and the pons ( - Fig. 1). On a heavy T2-weighted image, a clear margin was noted between the tumor and the brainstem, indicating the mass was located extra-axially (-Fig. 1d). This MR finding was also supported by tractography showing that the pyramidal tract was markedly compressed and displaced, but its continuity was maintained ( - Fig. 2a). Angiograms showed no tumor stain.

Because his clinical symptoms started with trochlear palsy, the most probable diagnosis was trochlear nerve schwannoma. We initially intended to achieve subtotal resection via a subtemporal approach. However, it was difficult to remove the lower part of the tumor, and compression on the pons remained on the postoperative imaging. Then we performed a second operation via the retrosigmoid approach to remove the lower part of the tumor ( - Fig. 2b). Intraoperative findings indicated the tumor originated from the trochlear nerve in the ambient cistern ( - Fig. $\mathbf{3}$ ). The excision was limited to the cysts and subtotal removal of the solid portion of the tumor. Although it was difficult to predict the functional prognosis of the impaired trochlear nerve by only an intraoperative finding, a small piece of tumor between the trochlear and the
License terms

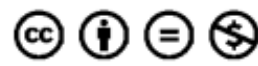

(c) 2015 Georg Thieme Verlag KG Stuttgart · New York 

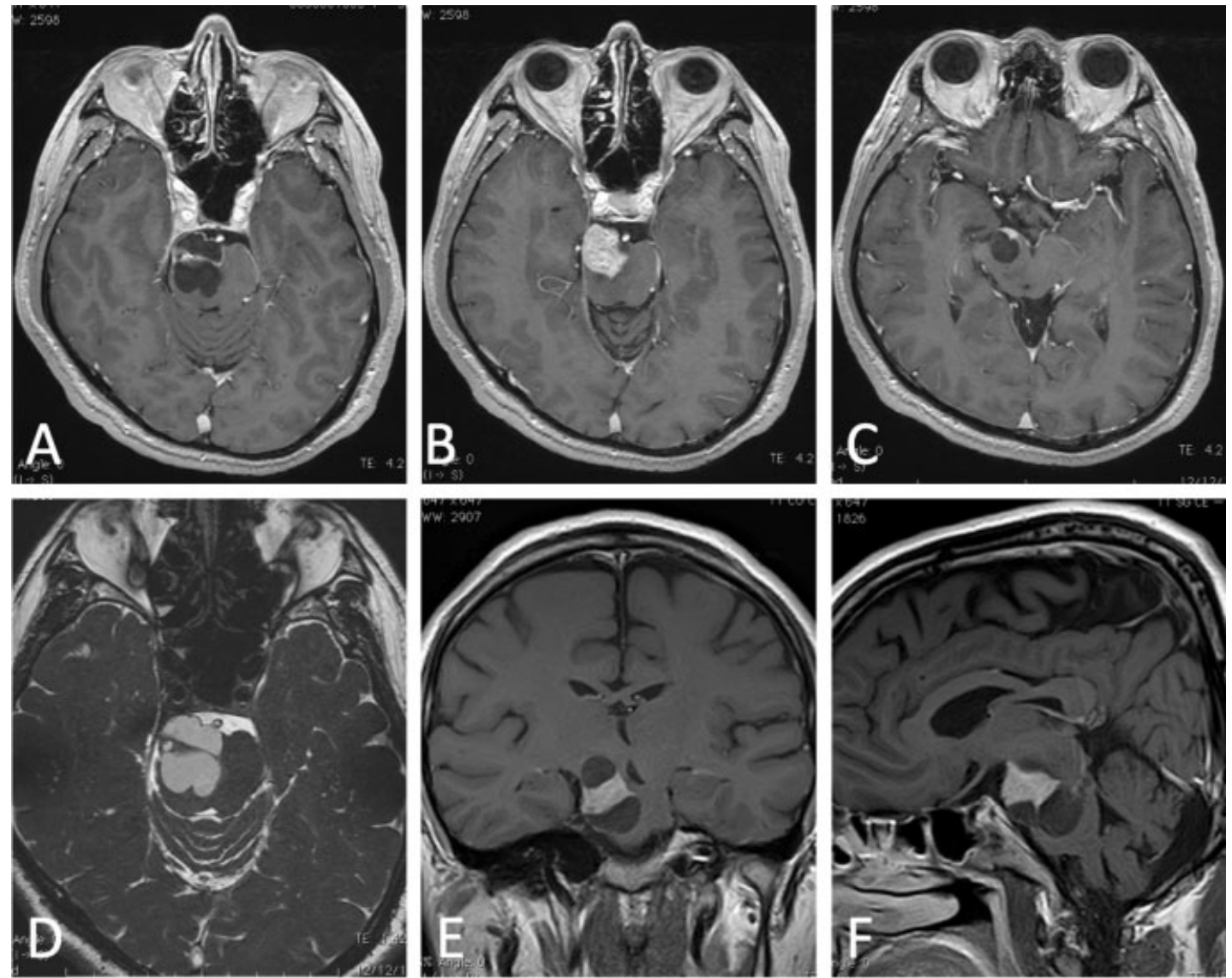

Fig. 1 Preoperative magnetic resonance imaging. (A-C) Axial T1-weighted images with gadolinium enhancement show a cystic mass with solid lesion in the center in the right ambient cistern compressing the brainstem. (D) A T2-weighted image shows cystic tumor around small solid portion compressing the pons. (E) Coronal and (F) sagittal images show the extent of the tumor reaching to the cerebral peduncle superiorly and pons inferiorly.
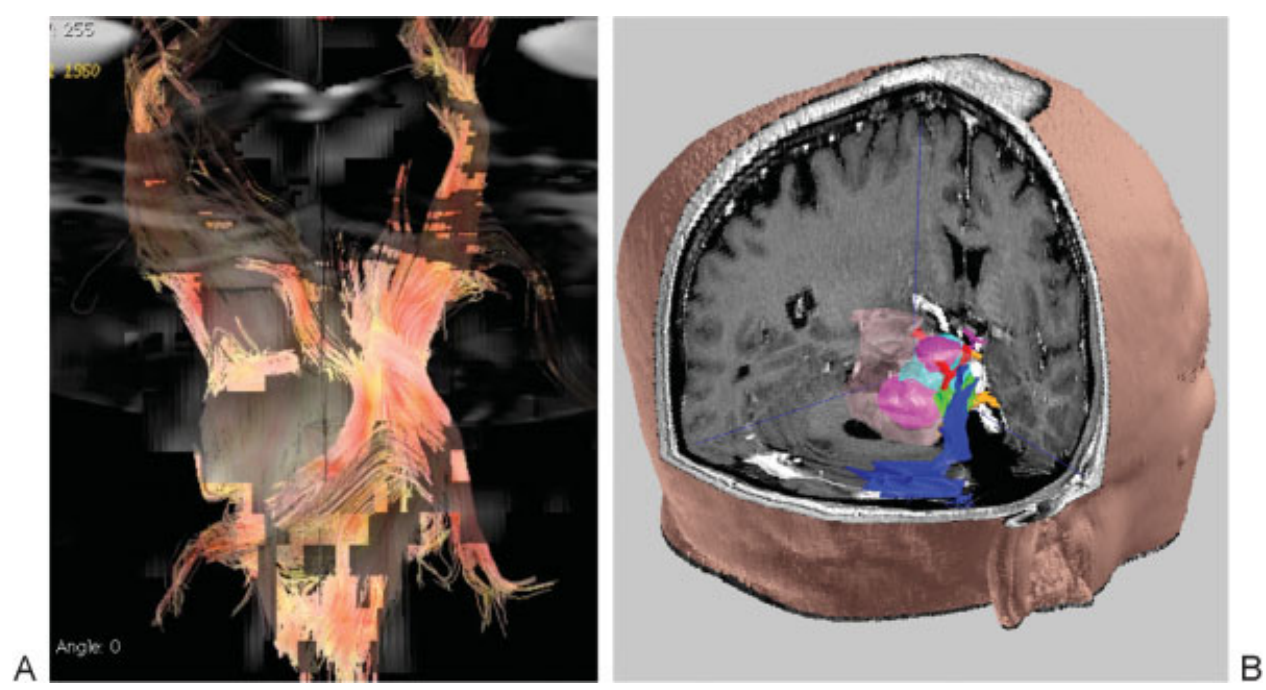

Fig. 2 Tractography and three-dimensional image. (A) A tractography shows compression on the corticospinal tract by the tumor. (B) A threedimensional preoperative image created by GammaPlan demonstrates anatomical relations around the tumor. Light blue shows solid portion of the tumor; pink shows the cystic portion. 


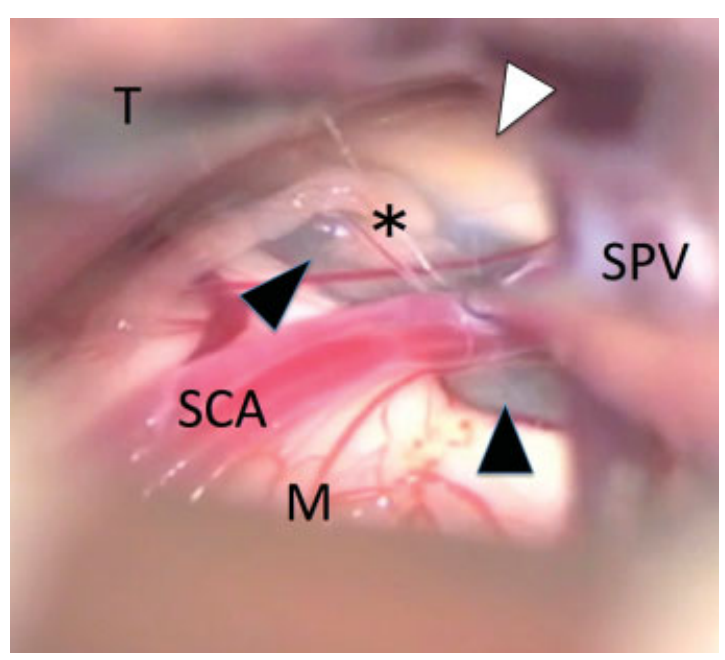

Fig. 3 Intraoperative view via retrosigmoid approach shows continuity of the trochlear nerve to the tumor. $\mathrm{M}$, midbrain; SCA, superior cerebellar artery; SPV, superior petrosal vein; T, tentorium. Asterisk, trochlear nerve; white arrowhead, solid portion of the tumor; black arrowheads, cystic portion of the tumor.

oculomotor nerves was left untouched to avoid further worsening of diplopia. We expected shrinkage of the remnant tumor by Gamma Knife would help improvement of his impaired nerve function. The histologic examination confirmed schwannoma (-Fig. 4).

Gamma Knife was applied to the residual tumor 3 months after the operation. The marginal dose was $12 \mathrm{~Gy}$ at 50\% isodose line on the residual tumor volume of $0.263 \mathrm{~cm}^{3}$, $\sim 8 \mathrm{~mm}$ average diameter ( $\sim$ Fig. 5a). The patient was followed up every 6 months thereafter. Diplopia subsided 6 months after resection. At the last visit, 12 months after Gamma Knife, the tumor was markedly reduced in size with decreased contrast enhancement ( $\mathbf{- F i g . 5 b ) . ~}$

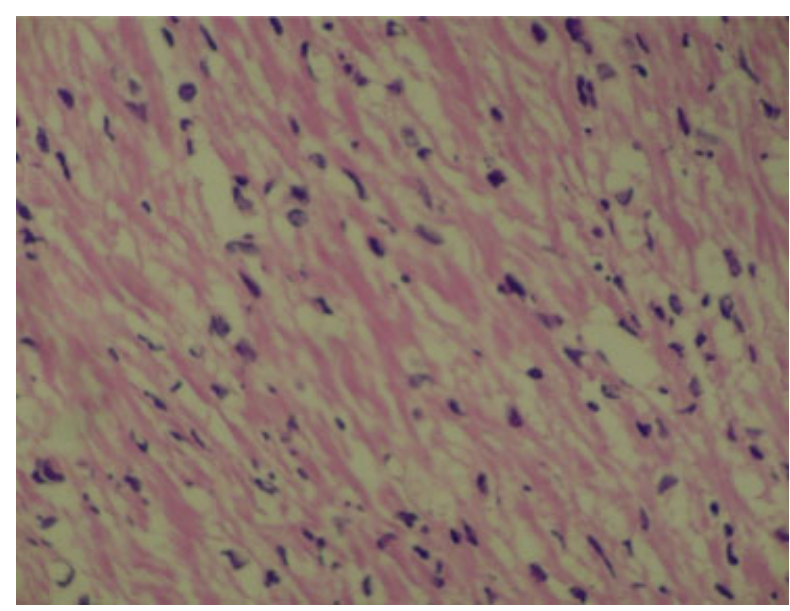

Fig. 4 Histologic examination shows typical schwannoma with occasional palisading of spindle cells in loosely structured background (Antoni B type). No mitosis or necrosis is apparent. Hematoxylin and eosin stain; original magnification $\times 400$.

\section{Discussion}

Although there are many reports on the effectiveness of stereotactic radiosurgery for vestibular schwannomas, there are only a few for nonvestibular schwannomas. ${ }^{3-8}$ Reports on Gamma Knife surgery for trochlear nerve schwannoma is even more limited. In our literature search, only 11 cases of trochlear nerve schwannomas treated by Gamma Knife are reported $(\boldsymbol{-}$ Table $\mathbf{1})$. The details of the treatment and followup are described in three of them. ${ }^{3,6,7}$ However, there was no histologic confirmation prior to radiosurgery. This is the first report on histologically confirmed trochlear nerve schwannoma treated by Gamma Knife.

Pollock et $\mathrm{al}^{8}$ reviewed 23 patients with nonvestibular schwannomas treated with Gamma Knife, including one patient with a trochlear nerve schwannoma. They reported satisfactory results of radiosurgery with a tumor control rate of $96 \%$ for the median follow-up period of 43 months. No clinical worsening was noted in the trochlear nerve schwannoma case. Elsharkawy et $\mathrm{al}^{5}$ reported 36 cases of nonvestibular schwannomas treated with Gamma Knife including one case of trochlear nerve schwannoma. Although the detailed clinical course is not described, they observed a reasonably effective result of Gamma Knife for nonvestibular schwannomas.

Kim et $\mathrm{al}^{6}$ reported the result of Gamma Knife surgery for schwannomas originating from oculomotor, trochlear, or abducens nerves including five cases of trochlear nerve schwannomas. Symptom was diplopia in all five cases. They treated them at a marginal dose of 12.5 to 13 Gy with Gamma Knife. Although the tumors were relatively small, ranging from 0.03 to $1.7 \mathrm{~cm}^{3}$, they observed a radiologic reduction in size in 4 to 42 months with clinical improvement of diplopia in four of five cases. Petrela et $\mathrm{al}^{7}$ also reported a detailed clinical course of two cases of trochlear nerve schwannoma treated with Gamma Knife. One patient treated with 14 Gy at $70 \%$ isodose line showed good recovery from diplopia within a few months after treatment as well as a reduction in size 2 years after Gamma Knife.

Therefore Gamma Knife surgery could contribute to manage relatively small trochlear nerve schwannomas with possible improvement of diplopia. In the present case, we also observed tumor shrinkage within 1 year after Gamma Knife surgery. This response is better than for vestibular schwannomas.

Only 32 cases of surgical excision of trochlear nerve schwannomas were reported from 1976 to $20144^{1,2}$ Surgical resection was undertaken via subtemporal, retrosigmoid, anterior or posterior transpetrosal, or pterional approaches depending on tumor locations. , $^{1,9-15}$ However, morbidity associated with surgical resection can be substantial due to the fourth nerve injury. Only one patient showed improvement of diplopia after subtotal excision. ${ }^{15}$ Most of the patients developed permanent and complete fourth cranial nerve palsy postoperatively, suggesting it is very difficult to remove these tumors without compromising cranial nerve function. Trochlear nerve schwannomas may present as large cystic tumors with a small solid portion. ${ }^{9,10,14}$ Such cystic tumors 

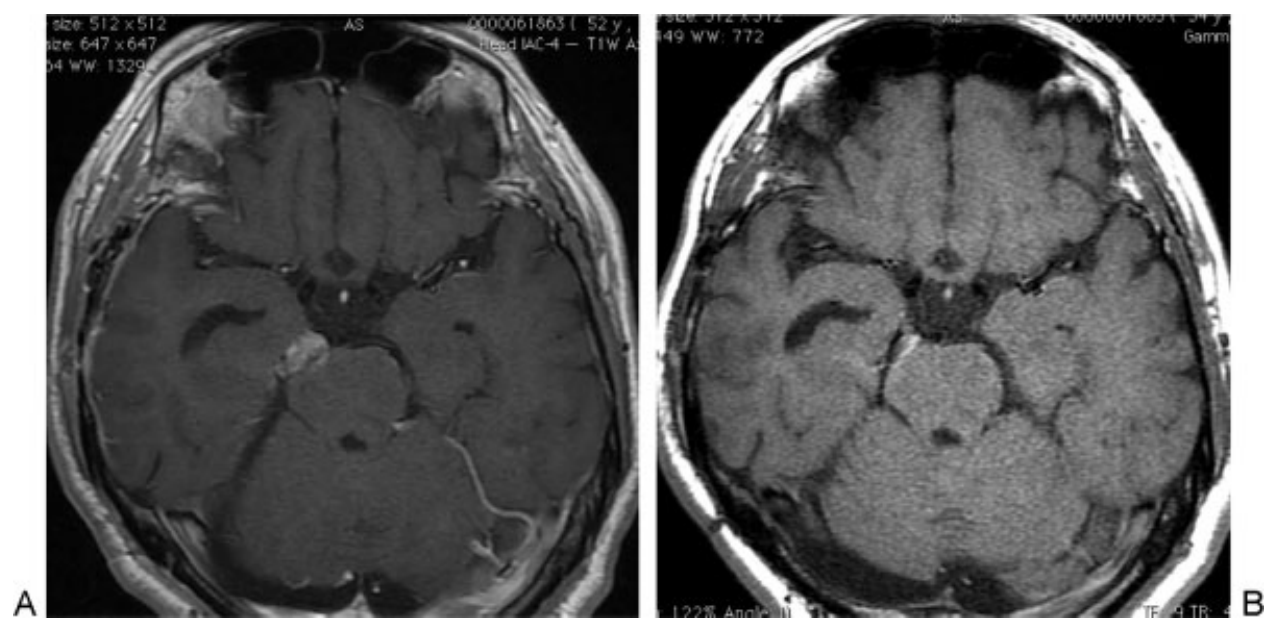

Fig. 5 Magnetic resonance (MR) imaging before and after Gamma Knife surgery. (A) A T1 gadolinium (Gd)-enhanced MR image before Gamma Knife surgery showing small remnant in the ambient cistern. (B) A T1 Gd-enhanced MR image 1 year after Gamma Knife surgery shows shrinkage of the tumor with decreased contrast enhancement.

can extend from the ambient cistern into the interpeduncular cistern as well as inferiorly into the upper part of the cerebellopontine cistern. In case the tumor shows mass effect by compressing the neighboring structures, surgical excision should be recommended. In our case, because the tumor showed progressive mass effect, the patient underwent immediate resection. Fortunately, his diplopia subsided in 6 months after the operation, and the residual tumor was successfully controlled by Gamma Knife.

Elmalem et al reported 30 cases of presumed trochlear nerve schwannoma. ${ }^{4}$ They found no significant changes in size in the patients without intervention during the mean follow-up period of 3.1 years. Of these, only three patients received surgical excision or Gamma Knife radiosurgery during the follow-up period. They concluded patients with isolated fourth nerve palsy and small lesions on the fourth nerve have a good prognosis and should be followed with serial MRI scans without neurosurgical intervention unless they develop signs of brainstem compression. Feinberg et $\mathrm{al}^{16}$ reported six cases of trochlear nerve schwannoma, $>5 \mathrm{~mm}$ in greatest diameter, of 221 patients with trochlear nerve palsy. Five of these patients remained stable during the mean follow-up period of 15.6 months. None of these patients have developed additional symptom of neurologic involvement. They concluded the patients with small trochlear nerve schwannomas may not require neurosurgical intervention.

From our result and literature review of trochlear nerve schwannomas, surgical excision would be better limited to

Table 1 Literature review of trochlear nerve schwannomas treated by Gamma Knife surgery

\begin{tabular}{|c|c|c|c|c|c|c|c|c|c|}
\hline Study & $\begin{array}{l}\text { No. of } \\
\text { patients }\end{array}$ & Symptom & $\begin{array}{l}\text { Prior } \\
\text { surgery }\end{array}$ & $\begin{array}{l}\text { Tumor } \\
\text { size }\end{array}$ & $\begin{array}{l}\text { Marginal } \\
\text { dose }\end{array}$ & $\begin{array}{l}\text { Follow- } \\
\text { up }\end{array}$ & $\begin{array}{l}\text { Tumor } \\
\text { control }\end{array}$ & $\begin{array}{l}\text { Clinical } \\
\text { outcome }\end{array}$ & $\begin{array}{l}\text { Compli- } \\
\text { cations }\end{array}$ \\
\hline $\begin{array}{l}\text { Pollock et al, } \\
2002^{8, a}\end{array}$ & 1 & NA & $\mathrm{NA}$ & NA & NA & $4-42$ & $\mathrm{NA}$ & NA & $\mathrm{NA}$ \\
\hline Kim et $\mathrm{al}^{6}$ & 5 & Diplopia in 5 & No & $\begin{array}{l}0.03 \\
-1.7 \mathrm{~cm}^{3}\end{array}$ & $12.5-13$ & 2 & $\begin{array}{l}\text { Reduced } \\
\text { in } 5\end{array}$ & $\begin{array}{l}\text { Improved } \\
\text { in } 4 \text {; } \\
\text { no change } \\
\text { in } 1\end{array}$ & No \\
\hline 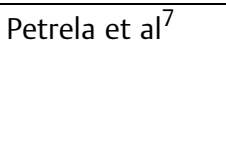 & 2 & Diplopia in 2 & No & $\begin{array}{l}0.039 \\
-0.168 \mathrm{~cm}^{3}\end{array}$ & $13-14$ & 48 & $\begin{array}{l}\text { Reduced } \\
\text { in } 2\end{array}$ & $\begin{array}{l}\text { Improved } \\
\text { in } 1 \text {; } \\
\text { no change } \\
\text { in } 1\end{array}$ & No \\
\hline Elflein et $\mathrm{al}^{3}$ & 1 & Diplopia & No & $\begin{array}{l}8 \mathrm{~mm} \\
\text { in diameter }\end{array}$ & NA & $\mathrm{NA}$ & Reduced & No change & No \\
\hline Elmalem et $a^{4, a}$ & 1 & Diplopia & No & NA & NA & $\mathrm{NA}$ & $\mathrm{NA}$ & NA & $\mathrm{NA}$ \\
\hline $\begin{array}{l}\text { Elsharkawy } \\
\text { et } \mathrm{al}^{5, \mathrm{a}}\end{array}$ & 1 & NA & NA & NA & NA & NA & NA & NA & $\mathrm{NA}$ \\
\hline Present case & 1 & Diplopia & Yes & $0.263 \mathrm{~cm}^{3}$ & 12 & 12 & Reduced & Improved & No \\
\hline
\end{tabular}

Abbreviation: NA, not applicable.

${ }^{a}$ No individual clinical data are available. 
large ones with mass effect; small tumors have a good prognosis without intervention. Surgical resection should be limited to subtotal or subcapsular decompression because Gamma Knife surgery is effective for the remnant tumor, and improvement of diplopia can be expected.

\section{Patient Consent}

The patient consented to the discussion of the case report for submission to the journal.

\section{References}

1 Boucher AB, Michael LM II. The middle fossa approach for the removal of a trochlear schwannoma. Case Rep Neurol Med 2014; 2014:672314

2 Hatae R, Miyazono M, Kohri R, Maeda K, Naito S. Trochlear nerve schwannoma with intratumoral hemorrhage presenting with persistent hiccups: a case report. J Neurol Surg Rep 2014;75(1): e183-e188

3 Elflein HM, Thömke F, Müller-Forell W, Pitz S. Trochlear palsies caused by isolated trochlear schwannomas. Strabismus 2010; 18(3):83-86

4 Elmalem VI, Younge BR, Biousse V, et al. Clinical course and prognosis of trochlear nerve schwannomas. Ophthalmology 2009;116(10):2011-2016

5 Elsharkawy M, Xu Z, Schlesinger D, Sheehan JP. Gamma Knife surgery for nonvestibular schwannomas: radiological and clinical outcomes. J Neurosurg 2012;116(1):66-72
6 Kim IY, Kondziolka D, Niranjan A, Flickinger JC, Lunsford LD. Gamma Knife surgery for schwannomas originating from cranial nerves III, IV, and VI. J Neurosurg 2008;109(Suppl):149-153

7 Petrela E, Hodge CJ, Hahn SS, Chung CT, Mejico LJ. Stereotactic radiosurgery in two cases of presumed fourth cranial nerve schwannoma. J Neuroophthalmol 2009;29(1):54-57

8 Pollock BE, Foote RL, Stafford SL. Stereotactic radiosurgery: the preferred management for patients with nonvestibular schwannomas? Int J Radiat Oncol Biol Phys 2002;52(4):1002-1007

9 Bartalena T, Leoni C, Trossello MP, et al. Hourglass cystic schwannoma of the trochlear nerve. Acta Biomed 2010;81(2):147-150

10 Gerganov V, Amir S, Koerbel A, Brandes A, Stan A, Madjid S. Cystic trochlear nerve schwannoma. Case report. Surg Neurol 2007; 68(2):221-225

11 Kohama M, Murakami K, Endo T, Watanabe M, Tominaga T. Surgical and histological observations of trochlear neurinoma: case report. Neurol Med Chir (Tokyo) 2009;49(5):217-220

12 Ohba S, Miwa T, Kawase T. Trochlear nerve schwannoma with intratumoral hemorrhage: case report. Neurosurgery 2006;58(4): E791; discussion E791

13 Santoreneos S, Hanieh A, Jorgensen RE. Trochlear nerve schwannomas occurring in patients without neurofibromatosis: case report and review of the literature. Neurosurgery 1997;41(1): 282-287

14 Shenoy SN, Raja A. Cystic trochlear nerve neurinoma mimicking intrinsic brainstem tumour. Br J Neurosurg 2004;18(2):183-186

15 Younes WM, Hermann EJ, Krauss JK. Cisternal trochlear nerve schwannoma: improvement of diplopia after subtotal tumour excision. Br J Neurosurg 2012;26(1):107-109

16 Feinberg AS, Newman NJ. Schwannoma in patients with isolated unilateral trochlear nerve palsy. Am J Ophthalmol 1999;127(2): 183-188 